\title{
EFFECTS OF SIX PERSONALITY FACTORS OF CEOS AT SMALL AND MEDIUM-SIZED ENTERPRISES ON PERFORMANCE IN BUSINESS MANAGEMENT: FOCUSING ON LEARNING AND GROWTH
}

\author{
Man-pil Han'1, Bong-ihn Seok², and Joon-ho Kim ${ }^{3 *}$ \\ 'Department of Business Administration, Chungbuk National University, \\ 1, Chungdae-ro, Seowon-gu Cheongju-si, Chungcheongbuk-do, Republic of Korea \\ ${ }^{2}$ Project Planning Team, Korea Institute for Advancement of Technology, 305, Teheran-ro, \\ Gangnam-gu, Seoul, Republic of Korea \\ ${ }^{3}$ Department of Business Administration, Sejong University, 202, 108-20, Songpa-dong, \\ Songpa-gu, Seoul, Republic of Korea \\ *Corresponding author: kshy4u@naver.com
}

Published date: 29 December 2017

To cite this article: Han, M.-P., Seok, B.-I., and Kim, J.-H. (2017). Effects of six personality factors of CEOs at small and medium-sized enterprises on performance in business management: Focusing on learning and growth. Asian Academy of Management Journal, 22(2), 97-128. https://doi.org/10.21315/aamj2017.22.2.4

To link to this article: https://doi.org/10.21315/aamj2017.22.2.4

\begin{abstract}
For the continual growth of small and medium-sized enterprises (SMEs) in the era of quickly changing economic paradigms, the role of the chief executive officer (CEO) is more important than ever. Because the role of a CEO is the core factor determining performance in business management, the behavioural characteristics of CEOs can determine the outcomes in a company. This study was conducted from the viewpoint that personality factors contribute to behavioural characteristics. The causal relationships were analysed among the six HEXACO personality factors (honesty-humility, extroversion, conscientiousness, agreeableness, openness to experience, and emotionality), the learning and growth of organisations, and performance in business management. For this purpose, a survey was conducted of the current CEOs of SMEs over a period of approximately 10 months, extending from 21 May 2015 to 22 February 2016. A total of 172 valid data were collected and used for the analysis of this study, and the results were as follows. First, among the six personality factors of CEOs, conscientiousness and openness to experience were shown to have a positive effect on learning and growth, determining the organisation's work management and innovation. Second, agreeableness was shown to have a positive

(C) Asian Academy of Management and Penerbit Universiti Sains Malaysia, 2017. This work is licensed under the terms of the Creative Commons Attribution (CC BY) (http://creativecommons. org/licenses/by/4.0/).
\end{abstract}


effect on performance in business management. Third, learning and growth were shown to have positive effects on performance in business management.

Keywords: CEOs of SMEs, six HEXACO personality factors, learning and growth, performances in business management

\section{INTRODUCTION}

The paradigm of an industrial economy, which has been accumulating for the past 100 years, is facing rapid changes due to advancements in digital, internet, mobile, and life science technologies. Such rapid changes in the paradigm are significantly affecting the survival and growth of small and medium-sized enterprises (SMEs). Compared to large companies, SMEs have such weaknesses as insufficient management resources, low brand awareness, disadvantaged relationships with large companies, difficulty in obtaining funds, narrow business scopes, highly competitive environments, and high rates of failure (Kim \& Na, 2008). Furthermore, SMEs do not operate with capital or policies as large companies do, and they mostly do not separate ownership from management because they are operated privately. In such a management system, the chief executive officer (CEO) can be considered to have a powerful influence on the survival and growth of the SME. Therefore, the CEOs of SMEs must be able to actively respond to the changing environment, and to take over the competitive advantage, they should continuously develop techniques and execute new management strategies to conduct effective leadership (Park, 2005).

Previous studies related to SMEs have reported that the management methods and ability of CEOs in SMEs are very closely related to the survival of these companies and that CEOs' decisions have direct effects on business performance and sales. Therefore, the influences of CEOs at SMEs are much greater than in large companies, and competitiveness is determined by the CEO's ability to manage the business (e.g., Ahn \& Park, 2015; Kwahk, Choi, \& Baik, 2016; Seo \& Son, 2015).

Of course, the successful performance by an SME in its survival and growth does not only occur through the CEO's competency in business management. The SME is affected by diverse environmental factors, since a company can grow continuously with stable and secure environmental factors, such as governmental support, or related organisations, consumers, and economic conditions (Park \& Kim, 2014). In previous studies related to the factors determining the competitiveness of domestic companies, obtaining excellent human resources and their utilisation were most frequently indicated as core factors in a company's competitiveness. However, 
if there is a lack of CEO leadership, distortion in management methods, or errors in the making of decisions, a management system cannot be constructed for the utilisation of excellent human resources and expertise; therefore, it will be difficult to enhance the competitiveness of the business (Park \& Lee, 2011). In the case of SMEs, the characteristics of the CEO constitute the core factors determining the competitiveness and successful performance of the business.

Among the studies related to the CEO characteristics that determine the outcomes and competitiveness of SMEs, the following areas have been most frequently studied: background and capacity (e.g., Davis, Babakus, Englis, \& Pett, 2010; Lee \& Kim, 2003; Mazzi, 2011; Park, 2005; Park \& Lee, 2011; Soriano \& Castrogiovanni, 2012; Thong \& Yap, 1995); leadership (e.g., Blackburn, Hart, \& Wainwright, 2013; Chung \& Park, 2010; Kim, 2007; Zhao, Seibert, \& Lumpkin, 2010); and entrepreneurial spirit (e.g., Buyl, Boone, Hendriks, \& Matthyssens, 2011; Daily \& Dalton, 1992; Kim \& Jung, 2015; Won, Hong, \& Cha, 2015). In these studies, the CEO's characteristics were shown to affect organisational effectiveness, business performance, and export performance through innovative activities related to the learning ability of the organisation, organisational culture, and technological development.

Since the basic characteristics of a CEO are based on personality factors, the personality of the CEO can influence the business performances (Nadkarni \& Herrmann, 2010; Spain, Harms, \& LeBreton, 2014). The CEO's characteristic can vary depending on the CEO's personality in the following areas: leadership style (Kwahk, 2013), flexibility in strategies (Nadkarni \& Herrmann, 2010), job performance level (Spain, Harms, \& LeBreton, 2014; Yoo, 2007), capacity of managing the organisation (Kim \& Yu, 2003), and entrepreneurial spirit (Park \& Kim, 2014). Therefore, personality factors are closely related to organisational capacity and business performance. In particular, in aspects in which CEOs of SMEs play critical roles in the growth and successful performance of business organisations, the CEO's personality can be an important factor affecting the performance of a company.

However, as suggested above, previous studies of the CEOs of SMEs and their performance in business management have only analysed externally expressed characteristics. To overcome such limitations, we considered that management and performances might be influenced by CEOs personality factors, and we empirically analysed the relationship between learning and growth - which determine personality characteristics, job completion, and innovative characteristics - and performance in business management. This study is significant because it could provide insight for predicting the growth of a company using the personality 
characteristics of CEOs. The aim of this study is to first identify the relationships between the personality factors of CEOs and their learning and growth in SMEs in the Republic of Korea. Second, our aim is to analyse the relationships between the personality factors of the CEOs of SMEs in the Republic of Korea and performance in business management. Finally, we aim to identify the effects of learning and growth on performance in business management.

\section{THEORETICAL BACKGROUND}

\section{SMEs in South Korea}

In South Korea, the Enforcement Decree of the Framework Act on Small and Medium Enterprises stipulates the following scale standards for each industry. The manufacturing industry corresponds to cases in which the number of regular employees is less than 300 or the capital is less than 8 billion won. The mining, construction, and transportation industries correspond to situations in which the number of regular employees is less than 300 or the capital is less than 3 billion won. The wholesale and retail trade sectors are divided into sub-sectors in detail, and the number of regular workers ranges from 50 to 300 persons, with sales ranging from 5 billion to 30 billion won.

However, even if an enterprise meets the size criteria for SMEs, it is excluded from the SMEs if it is "a company that has $30 \%$ of the total number of issued shares of the company with total assets of 500 million won or more," or "it is a company that belongs to this group." In addition, enterprises with more than 1,000 employees, and companies with total assets more than 500 billion won are excluded from SMEs. Finally, among SMEs, the following companies are classified as small businesses. The mining, manufacturing, construction, and transportation enterprises with fewer than 50 workers are classified as small businesses, and for wholesalers and service workers, companies with fewer than 10 workers are classified as small businesses.

\section{Importance of Personality, Learning, and Growth of CEOs at SMEs in South Korea}

CEOs' competency and leadership are very important for SMEs in South Korea, where systems or system maintenance is insufficient compared to large corporations in South Korea. The reason for this difference is that large companies in South Korea can manage even if the employees change, since their systems or regulations are well-organised. In contrast, when an SME changes its startup members or CEO, 
it can have difficulty operating the organisation, or the company's fate might even become uncertain (Gwak, Choi, \& Baik, 2016).

In other words, the CEOs of SMEs in South Korea must undergo continuous selfdevelopment, education, and training, have expertise in technology, and ultimately promote change and innovation. Furthermore, these CEOs should present the company vision to their employees and promote a fair working environment and proper delegation of authority to foster talented workers. These characteristics and virtues of South Korean SME CEOs are acquired through learning and growth (Park \& Lee, 2011).

The most important factor determining the success of a CEO in the context of a South Korean SME organisation is character. In other words, psychological factors, such as the character of the South Korean SME CEO, have sufficient flexibility in regard to the ability of the individual; therefore, it has been demonstrated that one can play the role of leader without being bound to various situations (Han $\&$ Kim, 2016). Therefore, the nature of South Korean SMEs emphasises that the character of the CEO is very closely related to the mission and performance of the organisation. In this study, we empirically tested the causal relationships among the six personality factors of South Korean SME CEOs, learning and growth, and management performance.

\section{HEXACO Model of Personality Structure}

There is a movement that recognises the existing Big 5 factors while additionally attempting to explain the remaining variables. There have been opinions about adding the honesty-humility factor, which has been proposed by studies based on cultures and languages outside of North America. For example, when one realises that one is about to experience a loss, a person with a degree of friendship would be "willing to help others," while a person with a high degree of honesty-humility would "rather accept the loss than trying to manipulate others." The personality model that reflects this viewpoint is also called the HEXACO model, which is an acronym (Park \& Kim, 2014; Rhee \& Lim, 2010).

One of the common criticisms of Big 5 is that it is too limited to Western cultures. Therefore, it has been argued that it is difficult to apply cross-culturally. The representative example is South Korea's affection and attachment culture. In fact, the psychological and social sciences often raise issues related to cultural universality, but many have noted that ambiguous concepts that are difficult to translate into English are included in the Big 5's measurement errors. For instance, for Westerners, to understand the filial piety of East Asian cultures, it should be 
accompanied by a long explanation, such as taking care of the mental and physical health of the elderly parents, continuing the family lineage, and bringing glory to the family name and ancestors (Park \& Kim, 2014; Rhee \& Lim, 2010). The differences between the Big 5 personality factors and the HEXACO personality factors can be determined as follows, according to previous studies.

To date, the studies of personality factors were based on the Big 5, consisting of five personality factors as follows: neuroticism, extroversion, openness to experience, agreeableness, and conscientiousness (Kim, 2008). However, many researchers (e.g., Ashton, Lee, \& Goldberg, 2004; Ashton \& Lee, 2002) have recently suggested that a sixth factor exists, which consists of the meaning of honesty/humility, exploitation, and arrogance. Ashton et al. (2004) suggested the HEXACO model with six personality factors, adding honesty-humility to the existing five factors, which is found commonly on international personality tests (Rhee \& Lim, 2010). The variables of personality have been studied since the early 1960s, and personality characteristics have been studied as five factors because the majority of research has used the list of adjectives created by Cattell (1943), to categorise personality factors; the study by Goldberg (1999) analysed five factors using factor analysis (Park \& Kim, 2014).

First, a difference between HEXACO and Big 5 is the factor of honesty-humility, which can be defined with the meanings of being honest, unpretentious, humble, and not greedy or cunning (Park \& Kim, 2014). The honesty-humility factor is not related to any of the factors of the Big 5, but it is related to the Machiavellian personality, indicating exploitation and manipulation, as well as antisociality (Ashton, Lee, \& Son, 2000). The subfactors are sincerity, fairness, greed avoidance, and modesty (Ashton et al., 2004). Second, emotionality includes the following as the subfactors: fearfulness, anxiety, dependence, and sentimentality. The neurotic factors in the Big 5, such as anger and irritability, are not included. Therefore, the difference lies in the factors of courage, confidence, anxiety, sensitivity, and emotionality being included, which did not play crucial roles in the Big 5 factors (Lee, Shin, Ryu, \& Heo, 2010). Third, agreeableness includes the following as subfactors: forgiveness, gentleness, flexibility, and patience. It includes the neurotic factors, anger and irritability, which are the subfactors of neuroticism in the Big 5. It also includes the contradicting variables, such as gentleness, flexibility, and patience (Lee et al., 2010).

Therefore, the differences between HEXACO and Big 5 are shown in the factors of honesty-humility, emotionality, and agreeableness. In contrast, the factors of extroversion, conscientiousness, and openness to experience are very similar. Extroversion has the following as subfactors: expressiveness, social boldness, 
sociability, liveliness, organisation, diligence, perfectionism, prudence, aesthetic appreciation, inquisitiveness, creativity, and unconventionality (Lee et al., 2010; Yoo, 2007).

The HEXACO model's six factors are additionally observed in other countries, such as Poland, the Philippines, and Turkey (Imperio, Church, Katigbak, \& Reyes, 2008; Szarota, Ashton, \& Lee, 2007; Wasti, Lee, Ashton, \& Somer, 2008), and their relationships with tolerance and risk taking have been studied (De Vries, De Vries, De Hoogh, \& Feij, 2009; Shepherd \& Belicki, 2008). Furthermore, there are studies comparing the phobic tendency within the Big 5 and HEXACO personalities, the development of HEXACO-IPIP, and the measurement itself (Ashton \& Lee, 2008). Domestically, Yoo, Lee, and Michael (2004) adapted the HEXACO model and analysed the validity of measurement by the six personality factors in the Korean version. Relevant to business organisations, Yoo (2007) tested the relationship of the six personality factors with variables such as task performance, contextual performance, and deviant behaviour. Lee et al. (2010) analysed the relationships of six personality factors with task performance and organisational citizenship behaviours. Rhee and Lim (2010) analysed the relationships of six personality factors with job satisfaction and organisational citizenship behaviours. Park and Kim (2014), based on the CEOs of SMEs, analysed the relationships of six personality factors with entrepreneurial spirit and business performance. Therefore, studies related to the six personality factors have been continuously conducted. In this study, we used the HEXACO model to empirically analyse the relationships among the personality types, learning and growth of business organisations, and performance in business management based on the CEOs in SMEs.

\section{Six Personality Factors and Learning and Growth}

Learning and growth form a substructure that allows goals or achievements from the internal perspective, customer perspective, and financial perspective, which are among the BSC (balanced score card) perspectives for measuring the performance of business management (Cho \& Kang, 2007). Learning and growth provide substructures such as employee capabilities, information systems capability, and motivation, as well as empowerment. Therefore, they not only affect the customer perspective, but they also play fundamental roles for other perspectives (Lee, 2005). Learning and growth are related to internal marketing and human resource management, so they are linked to job satisfaction, turnover intention, and production. They are determined by employee capability, education and training, and organisational culture (Cho \& Kang, 2007). 
Learning and growth can be affected by the characteristics of the CEO because employees' education, training, and organisational culture for learning and growth are affected by the CEO's support. These factors can also be found in studies analysing the influence of CEO characteristics in successful BSC. In previous studies, the CEO's leadership (Choe, Bae, \& Park, 2012), support for employees' education and training (Cavalluzzo \& Ittner, 2004; Song, 2008), emphases on changes and innovation (Cagwin \& Bouwman, 2002), fair task performance (Hyun, Pai, Shin, \& Chung, 2003), and delegation of authority (Ha, 2007) were shown to contribute to employee capability and motivation, which in turn were shown to enhance job satisfaction and to reduce turnover intention.

The precedence factors for enhancing learning and growth are influenced by the CEO's personality. In a study analysing personality factors and leaders' characteristics, De Vries (2012) indicated that honesty-humility is related to ethical leadership, extroversion is related to charismatic leadership, agreeableness is related to supportive leadership, and conscientiousness is related to taskoriented leadership. Kalshoven, Den Hartog, and De Hoogh (2011) reported that agreeableness tends to share authority, and it is related to a fair leadership style. Reichard et al. (2011) indicated that extroversion and agreeableness, as well as conscientiousness, were positively related to transformational leadership.

Therefore, the leaders' characteristics can vary depending on the personality factors, and they can influence performance from the perspectives of learning and growth. For instance, honesty-humility is related to ethical leadership, and it can enhance the perception of fairness regarding task performance among organisation members (De Vries, 2012). Furthermore, emotionality, which is among the Big 5 factors, has a significant relationship with role clarity, sharing of authority, and fairness (Kalshoven et al., 2011). Therefore, it has a high possibility of allowing for fair job performance and the delegation of authority to organisation members, and it can positively act on learning, growth, and performance enhancement. However, emotionality in HEXACO consists of negative personality subfactors, such as fearfulness, anxiety, and dependence. These personalities have a negative tendency towards supporting the learning and growth of organisation members and the business organisation's social responsibilities (Boddy, Ladyshewsky, \& Galvin, 2010; Spain et al., 2014). There is a possibility that it will result in the reduction of learning and growth. Agreeableness is a personality factor affecting cooperation and negotiation with others. Therefore, a highly agreeable person has greater potential of demonstrating devotion for one's organisation and organisational citizenship behaviours (Barrick, Mount, \& Strauss, 1993; Rhee \& Lim, 2010). A leader with a high level of agreeableness can show active support for the organisation's members compared to a task-oriented leader (Rhee \& 
Lim, 2010). Therefore, agreeableness can be inferred to have a positive effect on learning and growth. The conscientious leader pursues innovation, and this trait is linked to role clarity and fairness, which are also related to transformational leadership styles (Reichard et al., 2011). Therefore, conscientiousness, which is related to transformational leadership, can act positively on learning and growth. Extroversion is closely related to charismatic leadership (De Vries, 2012; Reichard et al., 2011). This type of leadership has characteristics of having a clear vision and being decisive, which organisation members to trust and follow their leader (Kwahk, 2013). Therefore, extroversion can have positive effects on learning and growth. Finally, the factor of openness to experience has the characteristic of having an experimental spirit and innovation, so it is related to transformational leadership style (Park \& Kim, 2014). A leader with openness to experience would emphasise innovation to organisation members, not be tied to conventionality, and would pursue creativity and uniqueness; therefore, such a leadership style can enhance learning and growth.

Many studies have been conducted related to personality factors and their relationships with organisational effectiveness within the area of organisational behaviours, as well as the relationship with academic achievement within the area of academic behaviours. These studies empirically demonstrate and emphasise the importance in that personality factors have direct and indirect impacts on organisational effectiveness and learning achievement.

Regarding agreeableness, Lee (2015) revealed that a high level of interpersonal relationships corresponded to a higher level of proactive learning, creativity, and problem-solving ability. Kim, Yim, and Chung (2015) showed that there is a strong correlation among interpersonal relations, self-directedness of learning, and academic achievement. Regarding conscientiousness and extroversion, Lee and Jang (2013) performed structural equation model analysis. As a result, these researchers showed that completeness had a positive effect on internal regulatory motivation, and conscientiousness had a positive effect on synchronized regulatory motivation, explaining that conscientiousness and completeness play important roles in the key personality factors that influence the motivation process (synchronized regulatory motivation), thereby enhancing academic involvement and the motivation process (internal regulatory motivation), which mediate academic involvement. Kang, Shin, Park, and Kim (2008) examined the predictive power of the learner's personality traits in their online academic activities and academic achievements. As a result, learners with high extroversion were found to have greater task management activities and extracurricular activities, and learners with high conscientiousness were found to have greater task-performing activities and social activities. 
Regarding openness, Yun and $\mathrm{Na}$ (2015) identified a causal relationship between self-directed learning preparation and cognition, learning motivation, job characteristics, and openness in organisational communication among office employees in large corporations. As a result, organisational variables, such as openness in organisational communication, were shown to have direct and indirect effect on self-directed learning readiness. Kang and Choi (2014) examined the effects of ethical leadership, task-oriented organisational culture, and learning at the organisational level on organisational effectiveness among e-learning company CEOs who are representatives of integrity (honesty/humility). Furthermore, they identified the structural relationships between these variables. As a result, the ethical leadership of a CEO at an e-learning company was shown to have a large, direct effect on the learning organisational level. The ethical leadership of the CEO of the e-learning company did not have any direct effects on organisational effectiveness, and it only showed indirect effects at the learning organisational level as a mediator. Finally, regarding emotionality, You (2012) examined the relationships among the variables that affect the academic delay behaviours of college students in e-learning environments. As a result, the following were selected as leading variables that influence academic delay behaviours, and the path model was configured: academic self-efficacy, perceived academic control, fear, and selfregulated learning. As a result of the analysis, fear was shown to have a positive, direct effect on academic delay behaviours, suggesting that, among representative personality factors, such as emotional distress, emotionality increases academic delay behaviours, which act as negative predisposing factors.

Concluding the above discussion, among the six personality factors, honestyhumility, extroversion, conscientiousness, agreeableness, and openness to experience were predicted to have positive effects on learning and growth. Emotionality was predicted to have a negative effect. Therefore, the following hypotheses were established:

H1.0: The six personality factors will have significant effects on learning and growth.

H1.1: Honesty-humility will have a positive effect on learning and growth.

H1.2: Extroversion will have a positive effect on learning and growth.

H1.3: Conscientiousness will have a positive effect on learning and growth.

H1.4: Agreeableness will have a positive effect on learning and growth.

H1.5: Openness to experience will have a positive effect on learning and growth.

H1.6: Emotionality will have a negative effect on learning and growth. 


\section{Six Personality Factors and Performance in Business Management}

From resource-based theory, performance in business management is the act of persistently obtaining and developing human and material resources and capacity, which can be enhanced by securing competitiveness (Seo \& Son, 2015). In particular, the performance of an SME can largely be determined by the CEO's ability and tendency (Cho \& Kim, 2011). The CEOs of SMEs are generally the owners, and they personally operate their companies; therefore, their decisions are the core variables determining their business performance (Ahn, Kim, \& Lee, 2010). This study targeted the CEOs of SMEs in South Korea. These CEOs have the characteristics of personally establishing their SMEs, and they directly operate their corporations as owners (largest shareowners). Therefore, the CEOs of SMEs in South Korea are the core factors in having a large influence on performance in business management. In the related previous studies, the following factors of the CEOs of SMEs were indicated to influence performance in business management: entrepreneurial spirit (Park \& Kim, 2014; Rauch \& Frese, 2007), innovative tendency (Seo \& Son, 2015; Ahn et al., 2010), motivation and self-efficacy (Park, 2005), and gender and age (Park, 2005).

The characteristics of CEOs that affect performance in business management at SMEs are generally variable according to their personalities. Kim (2003) reported the results of analysing MBTI types, targeted people in executive or higher positions. The results showed that they were more extroverted than introverted, more logical than emotional, and more judging than perceiving. Kwahk (2013) confirmed that leadership styles can vary depending on personality types, and reviewing the previous studies; he suggested that different leadership types could influence performance in business management. Yoo (2007) analysed the relationships between personality characteristics and job performance; Park and Kim (2014) analysed the relationships among personality characteristics, entrepreneurial spirit, and performance in business management; Rhee and Lim (2010) analysed the relationships between personality characteristics and job satisfaction; and Lee et al. (2010) analysed the relationships between personality characteristics and job motivation.

In a study analysing the relationships between personality characteristics and job performance, Yoo (2007) indicated that conscientiousness and extroversion are positively related to task performance, contextual performance, adaptive performance, and overall performance. Furthermore, conscientiousness, agreeableness, and honesty-humility are negatively related to deviant behaviours. Extroversion is positively related to task performance and overall performance. Agreeableness and honesty-humility are positively related to contextual 
performance. Therefore, Yoo implied that the quality of task performances could vary depending on personality characteristics, which could in turn lead to differences in performance. Park and Kim (2014) analysed the relationships of personality characteristics with entrepreneurial spirit and performance in business management, based on the CEOs of SMEs. Extroversion, conscientiousness, and openness to experience had positive relationships with entrepreneurial spirit, which in turn had a positive relationship with business performances. Based on these analyses, the personality characteristics of the CEOs of SMEs were suggested to affect entrepreneurial spirit which, in turn, affects business performance. Rhee and Lim (2010) indicated that extroversion, conscientiousness, and openness to experience had positive effects on job satisfaction, and extroversion and openness to experience had positive effects on organisational citizenship behaviours. Lee et al. (2010) analysed the relationships between personality characteristics and job motivation. The following were shown in their results: conscientiousness had an effect on the motivations for achievement and status; extroversion had an effect on the motivation for status; honesty-humility had an effect on organisational involvement; agreeableness had an effect on sociability; and job motivation had an effect on the task performance and organisational citizenship behaviours.

Based on the above previous studies that analysed the relationships between personality characteristics and performance, the following conclusions can be drawn. With the exclusion of emotionality, honesty-humility, extroversion, conscientiousness, agreeableness, and openness to experience had positive relationships with entrepreneurial spirit, job motivation, job satisfaction, and organisational citizenship behaviours. Therefore, these factors will positively affect the performance enhancement of a business organisation. Therefore, the following hypotheses were established:

H2.0: The six personality factors will have significant effects on performance in business management.

H2.1: Honesty-humility will have a positive effect on performance in business management.

H2.2: Extroversion will have a positive effect on performance in business management.

H2.3: Conscientiousness will have a positive effect on performance in business management.

H2.4: Agreeableness will have a positive effect on performance in business management. 
H2.5: Openness to experience will have a positive effect on performance in business management.

H2.6: Emotionality will have a negative effect on performance in business management.

\section{Learning and Growth and Performance in Business Management}

Learning and growth constitute an organisation's overall activity that reinforces the organisation's competitiveness, such as in employee capabilities, information systems capability, motivations, and delegation of authority (Calantone, Cavusgil, $\&$ Zhao, 2002). Learning and growth serve as the foundation for not only performance from a customer perspective but also performance from financial and other perspectives (Lee, 2005). In previous studies, learning and growth were indicated to enhance business performance by strengthening the ability to respond to the rapidly changing market, improving the business innovation (Calantone et al., 2002), and leading to success in new products (Sinkula, Baker, \& Noordewier, 1997). Chung and Park (2010) suggested that the learning orientation of a CEO in an SME enhances the innovation of the organisation and elevates performance in business management. Lee (2005) suggested that learning and growth, which are among the factors in BSC, can serve as a foundation for enhancing performance from financial, customer, and process perspectives.

In conclusion, learning and growth enhance job performance and innovation through the organisation members' knowledge development and motivation, and they increase competitiveness. Learning and growth positively act on performance in business management. Therefore, the following hypothesis was established:

H3.0: Learning and growth will have positive effects on performance in business management.

Based on the above discussions, the research model is as shown in Figure 1. 


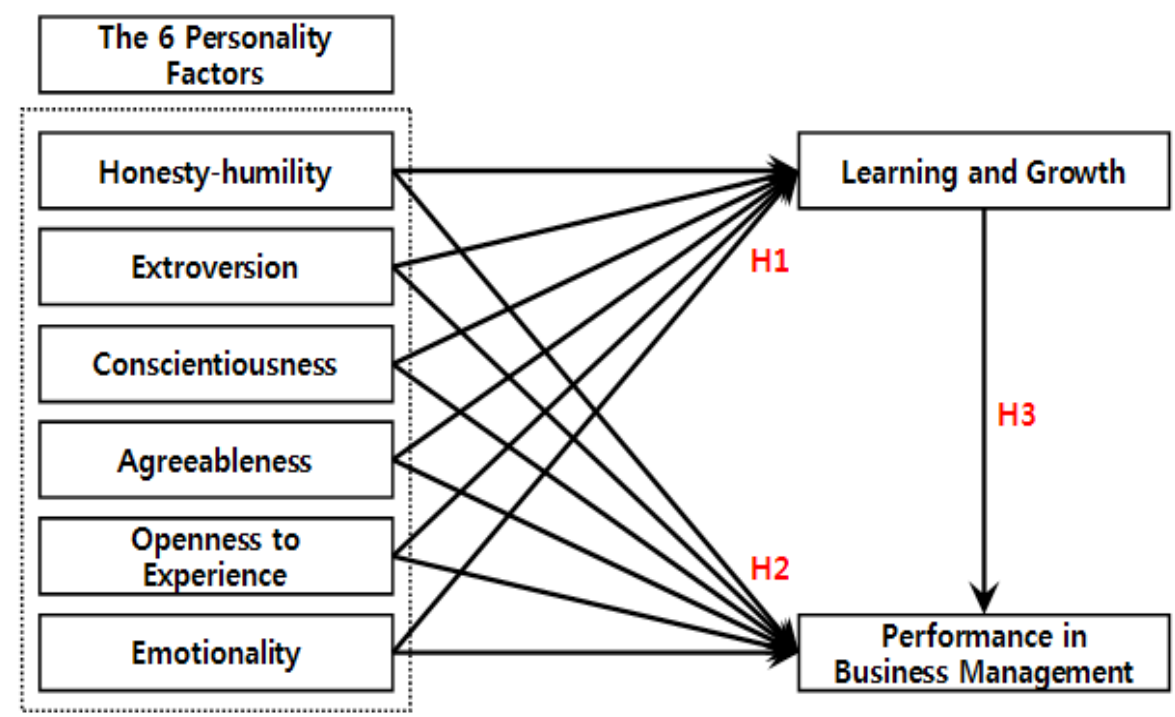

Figure 1. Research model

\section{RESEARCH METHODS}

\section{Study Targets and Data Collection}

The targets of this study are the CEOs of SMEs. In particular, in the SMEs of South Korea, CEOs make the decisions and give instructions to their employees. Therefore, the survey participants were the CEOs of SMEs, meeting the purposes of our study. In other words, the CEOs of SMEs in South Korea operate in a system in which they directly perform business management, control employees, and receive face-to-face reporting. Such specifics as the details of reports by employees and the degree of training could all be confirmed.

The duration of the survey was from 21 May 2015 to 22 February 2016 over an approximately 10-month period. The survey was conducted by the graduates of the Business Management course at K University. Since our survey was targeted to the CEOs of SMEs who attended or completed the CEO course at K University, we might have incurred partial bias that could be a limitation of our study. However, the CEOs of SMEs, which are the subjects of our study, are currently managing their businesses (retirees are excluded). Furthermore, the regions where SME CEOs manage their businesses are widely distributed within South Korea. Therefore, we determined that such bias might not have had a significant influence in the conducting of our survey. 
The first round of surveys was conducted at a monthly meeting for CEOs. With the exclusion of self-employed business owners, the CEOs at SMEs were targets for data collection. The subjects of this study are corporate owners (largest shareowners) who have personally established and are operating their companies. Prior to this study, the researcher directly contacted CEOs who were scheduled to attend monthly meetings for CEOs to request cooperation with this survey via phone conversations or text messages. For the members who were unable to provide responses at the monthly meeting, a second round of surveys was conducted by visiting them. After explaining the survey to the participants, the responses were collected through one-on-one interviews with the participants. In addition, we contacted personal acquaintances who are currently CEOs of SMEs to request cooperation with the survey. Approximately 200 questionnaires were distributed for the survey, and 188 questionnaires were collected (94\%). Among the received questionnaires, 16 with too many missing responses and repeated responses were excluded. A total of 172 (91.4\%) questionnaires were finally used for the statistical analysis in this study.

The general characteristics of the sample are shown in Table 1 . There were $82.6 \%$ men, constituting the majority of the sample. The age groups were $37.2 \%$ in their $50 \mathrm{~s}$ and $32.6 \%$ in their $40 \mathrm{~s}$. Regarding education level, a college degree or above was shown to be the most common at $44.2 \%$ and $20.9 \%$, respectively. The most common major that participants studied was science and engineering with $48.8 \%$. The year in which their companies started was most commonly 11-20 years ago with $43.0 \%$, followed by more than 20 years ago with $33.1 \%$. Regarding the number of employees, there were $77.9 \%$ with 50 employees. The type of business was most commonly production with $57.0 \%$. Regarding the question asking whether the industry to which their businesses belong was growing for the past five years, $70.3 \%$ responded that they had been growing, and 3.5\% responded that they have been decreasing.

\section{Measurement of Variables}

There are three core concepts of this study as follows: six HEXACO personality factors, learning and growth, and performance in business management. First, for the measurement items of six personality factors, 21 items from the previous studies by Lee et al. (2010) and Park and Kim (2014) were used, which were tested for reliability and validity. Learning and growth were measured using the following four items based on the study by Cho and Kang (2007): fair task performance, delegation of authority, changes and innovation, and education and training. Performance in business management was measured as financial performance and non-financial performance. 
Table 1

General characteristics of the sample descriptive statistics

\begin{tabular}{|c|c|c|c|}
\hline Division & Item & Frequency & $\%$ \\
\hline \multirow[t]{2}{*}{ Gender } & Male & 142 & 82.6 \\
\hline & Female & 30 & 17.4 \\
\hline \multirow[t]{4}{*}{ Age } & Under 30's & 15 & 8.7 \\
\hline & 40 's & 56 & 32.6 \\
\hline & 50 ’s & 64 & 37.2 \\
\hline & 60's and above & 37 & 21.5 \\
\hline \multirow[t]{4}{*}{ Education } & High school diploma & 38 & 22.1 \\
\hline & Associate degree & 22 & 12.8 \\
\hline & Bachelor's degree & 76 & 44.2 \\
\hline & Above college degree & 36 & 20.9 \\
\hline \multirow[t]{4}{*}{ Major } & Liberal arts & 26 & 15.1 \\
\hline & Commerce & 26 & 15.1 \\
\hline & Science and engineering & 84 & 48.8 \\
\hline & Others & 36 & 20.9 \\
\hline \multirow[t]{3}{*}{ Company's date of establishment } & Within past 10 years & 41 & 23.8 \\
\hline & $11-20$ years ago & 74 & 43.0 \\
\hline & Over 20 years ago & 57 & 33.1 \\
\hline \multirow[t]{3}{*}{ Number of employees } & Below 50 people & 134 & 77.9 \\
\hline & 50-100 people & 20 & 11.6 \\
\hline & Over 100 people & 18 & 10.5 \\
\hline \multirow[t]{5}{*}{ Type of business } & Service & 23 & 13.4 \\
\hline & Production & 98 & 57.0 \\
\hline & Retail and wholesale & 17 & 9.9 \\
\hline & IT & 6 & 3.5 \\
\hline & Others & 28 & 16.3 \\
\hline \multirow{3}{*}{$\begin{array}{l}\text { Growth of business in the industry } \\
\text { (for the past } 5 \text { years) }\end{array}$} & Growing & 121 & 70.3 \\
\hline & Maintaining & 45 & 26.2 \\
\hline & Reducing & 6 & 3.5 \\
\hline
\end{tabular}


The measurement items were based on previous studies by Shin and Yang (2010) and Kwon (2010), and they consisted of five items for financial performance, including the increase in sales and profits and financial security. For nonfinancial performances, four items were used, including automated tasks and the accuracy and handling of customer complaints. A 5-point Likert scale was used for the measurement. In the previous study by Shin and Yang (2010), the authors targeted on 100 Korean corporations (small and medium-sized corporations and mid-sized companies) that are in the electric, electronics, distribution, chemistry, and machinery industries performing international marketing activities. The relationship between corporations' global product management and operation performance (financial performance/non-financial performance) was examined.

\section{Validity and Reliability Analysis of the Measurement Tools}

\section{Exploratory factor analysis and reliability analysis}

To test the reliability and validity of the measurement items in this study, SPSS software version 18.0 (IBM, New York) was used, and exploratory factor analysis and reliability analysis were conducted. First, the results of validity and reliability analyses for the six personality factors are shown in Table 2. As a result of factor analysis, the following items were determined: four items in agreeableness, four items in conscientiousness, four items in extroversion, three items in openness to experience, three items in honesty-humility, and three items in emotionality. For the eigenvalue of each drawn factor, agreeableness was shown to be the highest with 4.719 , and emotionality was shown to be the lowest with 1.343 . The overall explanatory power was shown to be $63.312 \%$. As the result of reliability analysis, the $\alpha$ values were as follows: 0.703 for agreeableness, 0.784 for conscientiousness, 0.715 for extroversion, 0.702 for openness to experience, 0.698 for honestyhumility, and 0.671 for emotionality. The reliability coefficient regarding the six personality factors was shown to be relatively good.

Next, the results of validity and reliability analyses regarding learning and growth are shown in Table 3. As the result of performing factor analysis on the four items, learning and growth were considered as a single factor; the eigenvalue was 2.383, and the dispersion ratio was $59.579 \%$. As a result of reliability analysis, the $\alpha$ value was 0.763 , and the reliability coefficient was shown to be relatively good.

Finally, the validity and reliability analyses results regarding performance in business management are shown in Table 4 . As the result of performing factor analysis on the nine items, five items for financial performance and four items for non-financial performance, were determined. 
Man-pil Han et al.

Table 2

Factor analysis and reliability analysis (six personality factors)

\begin{tabular}{|c|c|c|c|c|c|c|}
\hline Factor & Item & $\begin{array}{l}\text { Load } \\
\text { value }\end{array}$ & $\begin{array}{l}\text { Eigen } \\
\text { value }\end{array}$ & $\begin{array}{c}\text { Dispersion } \\
\text { ratio } \\
(\%)\end{array}$ & $\begin{array}{l}\text { Accumulated } \\
\text { dispersion } \\
\text { ratio }(\%)\end{array}$ & $\begin{array}{c}\text { Cronbach's } \\
\alpha\end{array}$ \\
\hline \multirow[t]{4}{*}{ Agreeableness } & Flexibility & 0.774 & \multirow[t]{4}{*}{4.719} & \multirow[t]{4}{*}{22.470} & \multirow[t]{4}{*}{22.470} & \multirow[t]{4}{*}{0.703} \\
\hline & Gentleness & 0.741 & & & & \\
\hline & Forgiveness & 0.680 & & & & \\
\hline & Patience & 0.580 & & & & \\
\hline \multirow[t]{4}{*}{ Conscientiousness } & Diligence & 0.824 & \multirow[t]{4}{*}{2.300} & \multirow[t]{4}{*}{10.952} & \multirow[t]{4}{*}{33.421} & \multirow[t]{4}{*}{0.784} \\
\hline & Organisation & 0.812 & & & & \\
\hline & Perfectionism & 0.631 & & & & \\
\hline & Prudence & 0.605 & & & & \\
\hline \multirow[t]{4}{*}{ Extroversion } & Social boldness & 0.799 & \multirow[t]{4}{*}{1.951} & \multirow[t]{4}{*}{9.289} & \multirow[t]{4}{*}{42.711} & \multirow[t]{4}{*}{0.715} \\
\hline & Expressiveness & 0.798 & & & & \\
\hline & Sociability & 0.661 & & & & \\
\hline & Liveliness & 0.495 & & & & \\
\hline \multirow{3}{*}{$\begin{array}{l}\text { Openness to } \\
\text { experience }\end{array}$} & Unconventionality & 0.832 & \multirow[t]{3}{*}{1.527} & \multirow[t]{3}{*}{7.271} & \multirow[t]{3}{*}{49.982} & \multirow[t]{3}{*}{0.702} \\
\hline & Creativity & 0.817 & & & & \\
\hline & $\begin{array}{l}\text { Aesthetic } \\
\text { appreciation }\end{array}$ & 0.494 & & & & \\
\hline \multirow[t]{3}{*}{ Honesty-humility } & Fairness & 0.818 & \multirow[t]{3}{*}{1.457} & \multirow[t]{3}{*}{6.936} & \multirow[t]{3}{*}{56.918} & \multirow[t]{3}{*}{0.698} \\
\hline & Sincerity & 0.787 & & & & \\
\hline & Greed avoidance & 0.474 & & & & \\
\hline \multirow[t]{3}{*}{ Emotionality } & Anxiety & 0.856 & \multirow[t]{3}{*}{1.343} & \multirow[t]{3}{*}{6.395} & \multirow[t]{3}{*}{63.312} & \multirow[t]{3}{*}{0.671} \\
\hline & Fearfulness & 0.789 & & & & \\
\hline & Dependence & 0.525 & & & & \\
\hline
\end{tabular}

Table 3

Factor analysis and reliability analysis (learning and growth)

\begin{tabular}{llllccc}
\hline Factor & Item & $\begin{array}{c}\text { Load } \\
\text { value }\end{array}$ & $\begin{array}{c}\text { Eigen } \\
\text { value }\end{array}$ & $\begin{array}{c}\text { Dispersion } \\
\text { ratio } \\
(\%)\end{array}$ & $\begin{array}{c}\text { Accumulated } \\
\text { dispersion } \\
\text { ratio }(\%)\end{array}$ & Cronbach's $\alpha$ \\
\hline & $\begin{array}{l}\text { Fair job } \\
\text { performance }\end{array}$ & 0.867 & & & & \\
& $\begin{array}{l}\text { Delegation of } \\
\text { authority }\end{array}$ & 0.844 & & & & \\
$\begin{array}{l}\text { Learning } \\
\text { and } \\
\text { growth }\end{array}$ & $\begin{array}{l}\text { Changes and } \\
\text { innovation } \\
\text { Education and } \\
\text { training }\end{array}$ & 0.727 & 2.383 & 59.579 & 59.579 & 0.763 \\
& 0.626 & & & & \\
\hline
\end{tabular}


Table 4

Factor analysis and reliability analysis (performances in business management)

\begin{tabular}{|c|c|c|c|c|c|c|}
\hline Factor & Item & $\begin{array}{l}\text { Load } \\
\text { value }\end{array}$ & $\begin{array}{l}\text { Eigen } \\
\text { value }\end{array}$ & $\begin{array}{l}\text { Dispersion } \\
\text { ratio }(\%)\end{array}$ & $\begin{array}{l}\text { Accumulated } \\
\text { dispersion } \\
\text { ratio }(\%)\end{array}$ & $\begin{array}{c}\text { Cronbach's } \\
\alpha\end{array}$ \\
\hline \multirow[t]{5}{*}{$\begin{array}{l}\text { Financial } \\
\text { performances }\end{array}$} & $\begin{array}{l}\text { Increase in } \\
\text { company value }\end{array}$ & 0.809 & \multirow{5}{*}{3.938} & \multirow{5}{*}{43.751} & \multirow{5}{*}{43.751} & \multirow{5}{*}{0.814} \\
\hline & Increase in sales & 0.775 & & & & \\
\hline & Increase in profit & 0.718 & & & & \\
\hline & Financial security & 0.688 & & & & \\
\hline & Asset utilisation & 0.665 & & & & \\
\hline \multirow{4}{*}{$\begin{array}{l}\text { Non-financial } \\
\text { performances }\end{array}$} & Task processing & 0.793 & \multirow{4}{*}{1.393} & \multirow{4}{*}{15.474} & \multirow{4}{*}{59.226} & \multirow{4}{*}{0.760} \\
\hline & Automated task & 0.740 & & & & \\
\hline & $\begin{array}{l}\text { Accuracy in task } \\
\text { performance }\end{array}$ & 0.718 & & & & \\
\hline & $\begin{array}{l}\text { Handling } \\
\text { of customer } \\
\text { complaints }\end{array}$ & 0.687 & & & & \\
\hline
\end{tabular}

The eigenvalues were 3.938 for financial performance and 1.393 for non-financial performance, and the dispersion ratio was 59.226\%. As a result of reliability analysis, the $\alpha$ values were 0.814 for financial performance and 0.760 for nonfinancial performance. The reliability coefficient was shown to be relatively high.

In this study, we used LISREL software, version 8.72, to conduct the confirmatory factor analysis (CFA) for all of the factors and to perform the analysis using structural equation modelling. Confirmatory factor analysis is a method in which a specific hypothesis is set, and it shows how much of the relationship observed in the data can be explained. The researcher's previous knowledge and theoretical results are constructed into a model in the form of a hypothesis, and the model restricts a portion of the elements' values. According to Lomax and Schumacker (2012), the goodness of fit index, which evaluates the fitness of the model with actual data, is relatively less sensitive to the size of the sample. The GFI (goodnessof-fit index), CFI (comparative fit index), and RMSEA (root mean square error of approximation) are mostly considered since they reflect the conciseness of the model. In general, the fit of a model is considered to be good when GFI and CFI are close to 1 and RMSEA is between 0.05 and 0.08 . To evaluate the GFI of the model, the following were used: $\chi^{2}$, NFI (normed fit index), GFI, IFI (incremental fit index), TLI (Tucker Lewis index), and CFI. As the result of the analysis, the GFI of the research model was as follows: $\chi^{2}=954.455$, df $=297, p=0.00$; 
$\mathrm{NFI}=0.899 ; \mathrm{GFI}=0.834 ; \mathrm{IFI}=0.914 ; \mathrm{TLI}=0.904 ; \mathrm{CFI}=0.913 ;$ and RMSEA $=0.077$. The GFI was shown to be good overall, and the convergent validity and discriminant validity were both tested.

\section{Testing for Common Method Bias}

In this study, we used the same questionnaires to measure the dependent and independent variables, and the participants gave measurements on self-response forms. Therefore, common method bias could occur due to social desirability (Park, Kim, Jeong, \& Huh, 2007). To test for common method bias in this study, we performed Harman's one-factor test, based on the factor analysis results (Podsakoff \& Organ, 1986). According to Podsakoff and Organ (1986), when there is a critical amount of common method bias, a single factor can be drawn, or a general single factor can explain the majority of the dispersion that is drawn (Park \& Seol, 2011). We performed unrotated factor analysis for the measurement items of all of the included variables. As a result, nine factors were drawn, which had eigenvalues greater than 1. Among them, the first factor could only explain $21.093 \%$ of the overall dispersion. Therefore, common method bias can be considered to be not critical.

\section{EMPIRICAL ANALYSIS}

\section{Correlation Analysis}

The correlation analysis results of the measurement variables in this study are shown in Table 5. The correlations between the personality factors and learning and growth were shown to be significant at a significance level of 0.01 . When we observed the correlation coefficient between the personality factors and learning and growth, conscientiousness showed the highest correlation coefficient, followed by extroversion and openness to experience. In the correlation between the personality factors and financial performance, extroversion, conscientiousness, agreeableness, and openness to experience showed significantly positive correlations. Extroversion, conscientiousness, and agreeableness were also found to have significantly positive correlations with non-financial performance. In contrast, learning and growth not only had positive correlations with financial performance, but they also had highly positive correlations with non-financial performance. 
Table 5

Correlation analysis

\begin{tabular}{|c|c|c|c|c|c|c|c|c|c|c|}
\hline \multicolumn{2}{|c|}{ Factor } & \multirow{2}{*}{$\begin{array}{l}1 \\
1\end{array}$} & \multirow[t]{2}{*}{2} & \multirow[t]{2}{*}{3} & \multirow[t]{2}{*}{4} & \multirow[t]{2}{*}{5} & \multirow[t]{2}{*}{6} & \multirow[t]{2}{*}{7} & \multirow[t]{2}{*}{8} & \multirow[t]{2}{*}{9} \\
\hline 1 & Honesty-humility & & & & & & & & & \\
\hline \multirow[t]{2}{*}{2} & Extroversion & .303 & 1 & & & & & & & \\
\hline & & $(* *)$ & & & & & & & & \\
\hline \multirow[t]{2}{*}{3} & Conscientiousness & .368 & .362 & 1 & & & & & & \\
\hline & & $(* *)$ & $(* *)$ & & & & & & & \\
\hline \multirow[t]{2}{*}{4} & Agreeableness & .298 & .120 & .425 & 1 & & & & & \\
\hline & & $(* *)$ & & $(* *)$ & & & & & & \\
\hline \multirow[t]{2}{*}{5} & Openness to & .249 & .258 & .245 & .297 & 1 & & & & \\
\hline & experience & $(* *)$ & $(* *)$ & $(* *)$ & $(* *)$ & & & & & \\
\hline \multirow[t]{2}{*}{6} & Emotionality & .070 & .198 & .064 & .099 & .148 & 1 & & & \\
\hline & & & $(* *)$ & & & & & & & \\
\hline \multirow[t]{2}{*}{7} & Learning and & .230 & .343 & .388 & .235 & .295 & .217 & 1 & & \\
\hline & growth & $(* *)$ & $(* *)$ & $(* *)$ & $(* *)$ & $(* *)$ & $(* *)$ & & & \\
\hline \multirow[t]{2}{*}{8} & Financial & .077 & .159 & .381 & .281 & .224 & .131 & .410 & 1 & \\
\hline & performance & & $(*)$ & $(* *)$ & $(* *)$ & $(* *)$ & & $(* *)$ & & \\
\hline \multirow[t]{2}{*}{9} & Non-financial & .045 & 166 & .403 & .290 & .130 & .115 & .648 & .473 & 1 \\
\hline & performance & & $(*)$ & $(* *)$ & $(* *)$ & & & $(* *)$ & $(* *)$ & \\
\hline \multicolumn{2}{|c|}{ Mean } & 3.638 & 3.455 & 3.623 & 3.627 & 3.622 & 2.899 & 3.483 & 3.370 & 3.404 \\
\hline \multicolumn{2}{|c|}{ Standard deviation } & 0.740 & 0.599 & 0.643 & 0.592 & 0.597 & 0.746 & 0.604 & 0.573 & 0.612 \\
\hline
\end{tabular}

\section{Hypotheses Testing}

In this study, we conducted structural equation modelling using LISREL software, version 8.72, and the result of hypothesis testing are shown in Table 6. First, the following are the results of testing $\mathrm{H} 1.1$ to $\mathrm{H} 1.6$, which are related to the personality characteristics of CEOs of SMEs and learning and growth. Conscientiousness $(\beta=0.445, t=2.914, p<0.01)$ and openness to experience $(\beta=0.229, t=2.202$, $p<0.05)$ had directly positive effects on learning and growth. Therefore, H1.3 and H1.5 were supported. This finding occurred in the same context as in previous studies, suggesting that conscientiousness contributes to learning and growth (Reichard et al., 2011) and that openness to experience is related to a leadership style that emphasises experimental spirit and innovation (Park \& Kim, 2014). Therefore, the CEO of an SME can be considered to have the characteristics of handling task performances fairly, giving clear roles to the employees, and emphasising changes and innovation. These characteristics can be interpreted to play a role in facilitating learning and growth. 
However, honesty-humility, extroversion, agreeableness, and emotionality were not shown to have any significant effects on learning and growth. Therefore, H1.1, H1.2, H1.4, and H1.6 were not supported. The core reason why honesty-humility did not affect learning and growth is that honesty-humility is closely related to ethics and morality; however, such characteristics can be interpreted as having restrictions in leading innovation and forming creative organisations. This result occurs in the same context as in the previous study (Kalshoven et al., 2011), suggesting that honesty-humility has a close relationship with ethical leadership.

Extroverted leadership has a high possibility performing organisational citizenship behaviours for the employees to obtain interactions with employees or to gain attention. At the same time, this leadership style tends to look down on employees, so it could act as a cause diminishing organisation members' innovative activity and job satisfaction (Rhee \& Lim, 2010). In this context, extroversion is not predicted to have a significant effect on learning and growth.

Furthermore, highly agreeable CEOs in SMEs tend to be considerate in their relationships with employees. These CEOs have the characteristics of supportive leadership, which is about making the effort to provide support (De Vries, 2012). Such a leadership style focuses on maintaining agreeable relationships, rather than on the leader's charisma. Therefore, it is considered to have no effect on learning and growth, which emphasise innovation and changes.

Finally, emotionality is a personality type with negative aspects, such as anxiety and fearfulness. The result seems to show that this personality type has a high possibility of being passive regarding support for learning and growth (Spain et al., 2014).

Second, the following is the result of testing $\mathrm{H} 2.1$ to $\mathrm{H} 2.6$, which are related to personality characteristics and performance in business management. Agreeableness $(\beta=0.404, t=2.932, p<0.01)$ was the only factor that had positive effects on performance in business management. Therefore, H2.4 was supported. Agreeableness is a personality trait that considers the relationship with employees to be important. This definition supports the previous study (Lee et al., 2010) suggesting that agreeableness has positive effects on the organisational citizenship behaviours of employees, and organisational performance could be enhanced.

Honesty-humility, extroversion, conscientiousness, openness to experience, and emotionality did not have significant effects on performance in business management. Therefore, H2.1, H2.2, H2.3, H2.5, and H2.6 were not supported. In particularly, honesty-humility was shown to have a significantly negative effect 
on performance in business management. Such results could reveal the intensely competitive environment of SMEs, in which honesty-humility places restrictions on securing competitiveness. This finding occurred in a similar context in a previous study (Rhee \& Lim, 2010) reporting that honesty-humility did not have a significant effect on job satisfaction and organisational citizenship behaviours, and another previous study (Park \& Kim, 2014) indicated that honesty-humility did not have a significant effect on entrepreneurial spirit.

Since emotionality consists of negative sides of personality, our result supports the previous studies (Rhee \& Lim, 2010; Spain et al., 2014), which reported that such personality characteristics did not have significant effects on performance in business management.

Table 6

Result of hypotheses testing

\begin{tabular}{lccccl}
\hline Hypothesis & Direction & Path coefficient $(\beta)$ & S.E. & $t$-value & $\begin{array}{l}\text { Supported/Not } \\
\text { supported }\end{array}$ \\
\hline 1.1 & + & 0.135 & 0.107 & 1.261 & Not supported \\
1.2 & + & 0.079 & 0.126 & 0.625 & Not supported \\
1.3 & + & $0.445^{* *}$ & 0.153 & 2.914 & Supported \\
1.4 & + & -0.190 & 0.140 & -1.356 & Not supported \\
1.5 & + & $0.229^{*}$ & 0.104 & 2.202 & Supported \\
1.6 & - & 0.189 & 0.115 & 1.641 & Not supported \\
2.1 & + & $-0.358^{* *}$ & 0.105 & -3.423 & Not supported \\
2.2 & + & 0.006 & 0.109 & 0.058 & Not supported \\
2.3 & + & 0.118 & 0.140 & 0.842 & Not supported \\
2.4 & + & $0.404 * *$ & 0.138 & 2.932 & Supported \\
2.5 & + & -0.152 & 0.094 & -1.627 & Not supported \\
2.6 & - & -0.186 & 0.106 & -1.754 & Not supported \\
3.0 & + & $0.905^{* *}$ & 0.183 & 4.943 & Supported \\
\hline Goodness-of-fit statistics & $\chi^{2}=954.455, \mathrm{df}=297, p=0.00 ;$ NFI $=0.899 ;$ GFI $=0.834 ;$ \\
\hline
\end{tabular}

Note: $* p<0.05, * * p<0.01$

Extroversion, conscientiousness, and openness to experience are active characteristics. They are closely related to job performance and innovation, which require prudent planning. The previous studies (Lee et al., 2010; Park \& Kim, 2014) have suggested that, rather than having direct effects, these active personality factors would indirectly affect performance in business management 
through the entrepreneurial spirit, innovation, and job motivation. Therefore, the analytic results of our study are in agreement with the previous studies.

In contrast, learning and growth $(\beta=0.905, t=4.943, p<0.01)$ were shown to have highly positive effects on performance in business management. Therefore, H3.0 was supported. This result supports the previous study (Chung \& Park, 2010), indicating that learning and growth can serve as the basis for financial performance and customer performance.

\section{CONCLUSION}

In this study, we empirically analysed the relationships among the six HEXACO personality factors of CEOs in SMEs, the learning and growth, and performances in business management. The six personality factors are a new categorising tool with personality characteristics. Because this method is currently being empirically identified to supplement the limitations of the Big 5, the theme and research method of our study can be considered very timely. Furthermore, our study is significant in that it was targeted to CEOs of SMEs, who make up a critical portion of the national economy.

However, under the unrealistic premise that one's personality will not change, there are many limitations that follow: a person's personality does not always match the person's behaviours; people with similar personalities can have different behavioural characteristics; and there have been notably few previous studies examining personality and performance in business management that targeted the CEOs of SMEs. With many limitations, our study can be considered significant because it provides information for predicting the relationships among the personality characteristics of CEOs in SMEs and performance of their business management.

Therefore, the core study results that we derived are as follows. First, among the six personality factors, conscientiousness and openness to experience were shown to have positive effects on learning and growth. Therefore, a CEO's conscientiousness and openness to experience can affect an organisation's innovation and changes, and it has a tendency towards considering organisational justice to be important. Second, among the six personality factors, only agreeableness was shown to have a positive effect on performance in the business management of SMEs. It shows that performance in business management relies on the establishment of cooperative relationships based on agreeable personalities. Third, we revealed that learning and growth are critical variables for SMEs in their performance of business 
management. For the persistent growth of an SME, an organisation should be innovative, pursue changes, and maintain fairness.

Based on these results, the implications of this study are as follows. First, we constructed an integrative structural model and analysed the correlations among the interacting variables to identify the relationships among the six personality factors, learning and growth, and performance in business management. There have been many studies suggesting that CEO characteristics have influences on their performance in business management and that the personality types of CEOs have effects on their behavioural characteristics, such as leadership. However, there have been no studies analysing the influence of CEOs' personality characteristics on learning and growth and on the entire organisation. Therefore, our study introduced a new direction of research. Second, in the organisation of SMEs, learning and growth have strong effects on performance in business management. It was found that such organisational characteristics could be affected by the CEO's personality. Unlike in large companies, the CEOs of SMEs are equally important as their business organisations. In this era led by innovation, the active and progressive personality of a CEO can affect the entire organisation's innovation and fair operation. Ultimately, it can be used to secure the competitiveness that other companies cannot replicate. Third, we found that most of the six personality factors, with the exception of agreeableness, did not have direct effects on performance in business management. Instead, we found the possibility that the CEO's behavioural characteristics come from personality factors, and the organisational characteristics can affect performance in business management. Fourth, this study was the first targeting the CEOs of SMEs in South Korea to analyse the relationships among personality factors, learning and growth, and performance in business management, using structural equation model for statistical analysis. Particularly in the field of the social sciences, personality factors have been frequently studied in the area of psychology (social problems) using structural equation model. Furthermore, in the area of business management, studies have been conducted on organisational behaviours using surveys of general employees of corporation. Therefore, this study is significant because the personality factors of the CEOs of SMEs were examined using statistical methods.

Despite these implications, our study had the following limitations. First, the survey of our study was conducted in a self-response format to determine the respondents' personality factors. In the future, the measurement tool should be made more precise by adding third person responses and including sub-variable items of personality factors. Second, the sample was selected by convenience sampling based on the specific target. Therefore, errors could be present. To avoid biased study results, the sample should become more diverse. Third, the subjects of this study were the 
CEOs of SMEs in South Korea. Therefore, the study results cannot be applied to the CEOs of SMEs in other countries, and there are limitations to generalisation. In particular, the personality factors of CEOs might continue to change according to environmental factors, and these changes can be predicted to occur frequently. Therefore, we should find variables of contemporary environments and examine the causal relationships with personality factors to perform more elaborate studies. Fourth, our study only analysed the effects of the personality factors of CEOs of SMEs on learning and growth and performance in business management. The influence of personality should be analysed with a broader scope, and an integrative model, which can consider many of the preceding variables, should be built to test the correlation. Fifth, this study conducted statistical analysis using structural equation model. However, one of its limitations is that demographic characteristics (gender, age, education, etc.) are controlled, so they cannot be made into dummy variables. Specifically, structural equation modelling is a statistical technique that identifies causal relationships between variables in non-experimental situations. The structural equation model is a combination of a latent variable model, which shows causal relationships between latent variables, and a measurement model, in which the latent variables are measured as observed variables. For this reason, the structural equation model can be considered a combination of regression analysis and factor analysis. Additionally, since the structural equation model is a general linear model, the relationships between variables that are linearly represented can all be expressed using structural equation modelling. Therefore, it has the advantage of being able to use many statistical techniques as its sub-models. However, structural equation modelling sets the error term in the dependent variable to show that the error is not explained by the independent variable. However, by setting the control variables, a very complex model is established, leading to a very low degree of model fitness. In addition, there is a disadvantage that regression analysis and control variables are dummified, so they cannot be further analysed. As a result, it is very difficult to control the variables in the structural equation model. As a representative example, Seo and Son (2015) tested the causal relationships among the innovativeness, innovation performance, and business performance of SME CEOs using structural equation model analysis, and they did so without using control variables. Therefore, future studies should utilise the SPSS statistical software programme, which is more commonly used, to perform comparative analysis between demographic characteristics. 


\section{REFERENCES}

Ahn, K.Y., \& Park, R.G. (2015). The effect of small and medium enterprises CEO's leadership on knowledge management. Asia-Pacific Journal of Business Venturing and Entrepreneurship, 11(1), 29-38.

Ahn, K.Y., Kim, H.K., \& Lee, S.R. (2010). A study about the impacts of firm's innovation competence on management performance: Focusing on the SME in the medical equipment industry. Journal of Business Administration, 23(4), 2305-2328.

Ashton, M.C., \& Lee, K. (2002). Six independent factors of personality variation: A response to Saucier. European Journal of Personality, 16(1), 63-75. https://doi. org $/ 10.1002 /$ per.433

Ashton, M.C., \& Lee, K. (2008). The prediction of honesty-humility-related criteria by the HEXACO and five-factor models of personality. Journal of Research in Personality, 42(5), 1216-1228. https://doi.org/10.1016/j.jrp.2008.03.006

Ashton, M.C., Lee, K., \& Goldberg, L.R. (2004). A hierarchical analysis of 1,710 English personality-descriptive adjectives. Journal of Personality and Social Psychology, 87(5), 707-721. https://doi.org/10.1037/0022-3514.87.5.707

Ashton, M.C., Lee, K., \& Son, C. (2000). Honesty as the sixth factor of personality: Correlations with Machiavellianism, primary psychopathy, and social adroitness. European Journal of Personality, 14(4), 359-368. https://doi.org/10.1002/10990984(200007/08)14:4<359::AID-PER382>3.0.CO;2-Y

Barrick, M.R., Mount, M.K., \& Strauss, J.P. (1993). Conscientiousness and performance of sales representatives: Test of the mediating effects of goal setting. Journal of Applied Psychology, 78(5), 715-722. https://doi.org/10.1037/0021-9010.78.5.715

Blackburn, R.A., Hart, M., \& Wainwright, T. (2013). Small business performance: Business, strategy and owner-manager characteristics. Journal of Small Business and Enterprise Development, 20(1), 8-27. https://doi. org/10.1108/14626001311298394

Boddy, C.R., Ladyshewsky, R.K., \& Galvin, P. (2010). The influence of corporate psychopaths on corporate social responsibility and organizational commitment to employees. Journal of Business Ethics, 97(1), 1-19. https://doi.org/10.1007/ s10551-010-0492-3

Buyl, T., Boone, C., Hendriks, W., \& Matthyssens, P. (2011). Top management team functional diversity and firm performance: The moderating role of CEO characteristics. Journal of Management Studies, 48(1), 151-177. https://doi. org/10.1111/j.1467-6486.2010.00932.x

Cagwin, D., \& Bouwman, M.J. (2002). The association between activity-based costing and improvement in financial performance. Management Accounting Research, 13(1), 1-39. https://doi.org/10.1006/mare.2001.0175

Calantone, R.J., Cavusgil, S.T., \& Zhao, Y. (2002). Learning orientation, firm innovation capability, and firm performance. Industrial Marketing Management, 31(6), 515524. https://doi.org/10.1016/S0019-8501(01)00203-6

Cattell, R.B. (1943). The description of personality: Basic traits resolved into clusters. Journal of Abnormal and Social Psychology, 38(4), 476. https://doi.org/10.1037/ h0054116 
Cavalluzzo, K.S., \& Ittner, C.D. (2004). Implementing performance measurement innovations: Evidence from government. Accounting, Organizations and Society, 29(3), 243-267. https://doi.org/10.1016/S0361-3682(03)00013-8

Cho, J.H., \& Kim, C.J. (2011). A study on management performance factors on the small and micro business. Journal of Business Administration, 24(3), 1757-1773.

Cho, W.S., \& Kang, I.H. (2007). The impact of the strategic posture to the learning and growth perspective of BSC. Korean Journal of Hospitality and Tourism, 16(2), $1-17$.

Choe, D.W., Bae, B.H., \& Park, G.S. (2012). The analysis on the relevancy between CEO's leadership, corporate culture and utilization of BSC indicators in hotel industry. Regional and Industrial Research, 35(2), 91-114.

Chung, D.Y., \& Park, K.H. (2010). An influence of learning orientation in small and medium enterprise on corporate performance: Centered on mediating effect of market orientation and innovativeness. Journal of Business Education, 24(2), 153-176.

Daily, C.M., \& Dalton, D.R. (1992). The relationship between governance structure and corporate performance in entrepreneurial firms. Journal of Business Venturing, 7(5), 375-386. https://doi.org/10.1016/0883-9026(92)90014-I

Davis, P.S., Babakus, E., Englis, P.D., \& Pett, T. (2010). The influence of CEO gender on market orientation and performance in service small and medium-sized service businesses. Journal of Small Business Management, 48(4), 475-496. https://doi. org/10.1111/j.1540-627X.2010.00305.X

De Vries, R.E. (2012). Personality predictors of leadership styles and the self-other agreement problem. Leadership Quarterly, 23(5), 809-821. https://doi. org/10.1016/j.leaqua.2012.03.002

De Vries, R.E., De Vries, A., De Hoogh, A., \& Feij, J. (2009). More than the big five: Egoism and the HEXACO model of personality. European Journal of Personality, 23(8), 635-654. https://doi.org/10.1002/per.733

Goldberg, L.R. (1999). A broad-bandwidth, public domain, personality inventory measuring the lower-level facets of several five-factor models. Personality Psychology in Europe, 7(1), 7-28.

Gwak, K.Y., Choi, J.S., \& Baik, K.B. (2016). The moderating effect of CEO competency in the relations between SME CEO's issue leadership and SME performance. Korea Journal of Business Administration, 29(2), 195-212.

Ha, M.S. (2007). A study on the determining factors of the BSC effectiveness in the public administrative organization: Focused on central agencies in the Korean government. Korean Journal of Public Administration, 16(3), 31-68.

Han, M.P., \& Kim, B.G. (2016). Effect of executive officer's personality characteristics on balanced scorecard: Focusing on chief information officers. The e-Business Studies, 17(4), 123-142. https://doi.org/10.20462/TeBS.2016.08.17.4.123

Hyun, C.K., Pai, H.S., Shin, Y.J., \& Chung, M.H. (2003). The effect of the discrepancy between perceived importance and usage of BSC on the perception of fairness of performance appraisal. Korean Accounting Journal, 12(1), 1-34. 
Imperio, S.M., Church, A.T., Katigbak, M.S., \& Reyes, J.A.S. (2008). Lexical studies of Filipino person descriptors: Adding personality-relevant social and physical attributes. European Journal of Personality, 22(4), 291-321. https://doi. org/10.1002/per.673

Kalshoven, K., Den Hartog, D.N., \& De Hoogh, A.H. (2011). Ethical leader behavior and big five factors of personality. Journal of Business Ethics, 100(2), 349-366. https://doi.org/10.1007/s10551-010-0685-9

Kang, M.H., Shin, H.J., Park, M.S., \& Kim, M.J. (2008). Predicting power of learner's bigfive personality trait on online learning activities and academic achievement. The Korean Journal of Educational Methodology Studies, 20(1), 111-129.

Kang, Y.H., \& Choi, E.S. (2014). An analysis of structural relationships between e-learning company CEO's ethical leadership, task-oriented organizational culture, learning organization level, and organizational effectiveness. The Korean Journal of Human Resource Development Quarterly, 16(4), 113-142. https://doi.org/10.18211/ kjhrdq.2014.16.4.005

Kim, B.S. (2003). A study on the top executives' MBTI. Journal of Industrial Economics and Business, 16(5), 137-159.

Kim, B.S., \& Yu, G.C. (2003). Study on the personality types, styles of conflict management, and performances of executives. Korean Academy of Management, Conference Proceedings, 380-396.

Kim, H.R. (2008). An empirical study on the effects of personality and self-leadership of potential founders in the micro business area on founder self-efficacy: Applying the big five factors model and the self-leadership theory. Journal of Business Administration, 21(6), 2393-2420.

Kim, J.H., \& Jung, S.H. (2015). Study on CEO characteristics for management of public art performance centers. Journal of Open Innovation: Technology, Market, and Complexity, 1(1), 1-21. https://doi.org/10.1186/s40852-015-0007-7

Kim, K.H., \& Na, S.I. (2008). The causal relationship among learning orientation, learning behaviors, organizational environment and learning outcomes in small and medium enterprises. Journal of Employment and Skills Development, 11(3), 171192.

Kim, S.H., Yim, H.R., \& Chung, I.J. (2015). Does self-direction in learning influence interpersonal relationships in addition to academic achievement? Journal of Youth Welfare, 17(1), 305-322.

Kim, Y.J. (2007). An empirical study on the impacts of strategic leadership, R\&D investment, and human resource management practices on innovation performance. Journal of Organization and Management, 31(4), 49-83.

Kwahk, K.Y. (2013). Personality and leadership: Current research trends and future directions. Korean Leadership Quarterly, 4(4), 113-130.

Kwahk, K.Y., Choi, J.S., \& Baik, K.B. (2016). The moderating effect of CEO competency in the relations between SME CEO's issue leadership and SME performance. Korean Journal of Business Administration, 29(2), 195-212.

Kwon, Y.H. (2010). The study on the effect of fit between quality management and CSR to business performance. Journal of Business Administration, 23(5), 2775-2792. 
Lee, J.H., \& Kim, Y.W. (2003). Effects of technological capability, owners' characteristics, and organizational structures on financial performance. Asia Pacific Journal of Small Business, 25(4), 79-112.

Lee, J.H., Shin, K.H., Ryu, J.H., \& Heo, C.G. (2010). The mediating role of motivation in its relationship between personality and task, organizational citizenship behavior. Korean Journal of Management, 18(3), 1-33.

Lee, J.S. (2005). Marketing mix and performance for hotels. Korean Journal of Hospitality and Tourism, 14(3), 89-110.

Lee, J.Y., \& Jang, H.S. (2013). Effects of conscientiousness and perfectionism on academic engagement: Mediation effects of self-regulation. Korean Journal of Social and Personality Psychology, 27(2), 127-142.

Lee, Y.M (2015). The effect on creative personality, problem solving ability and human relationship by learner-centered teaching method on pre-learning. The Journal of Creativity Education, 15(4), 117-131.

Lomax, R.G., \& Schumacker, R.E. (2012). A beginner's guide to structural equation modeling. New York, NY: Routledge Academic.

Mazzi, C. (2011). Family business and financial performance: Current state of knowledge and future research challenges. Journal of Family Business Strategy, 2(3), 166181. https://doi.org/10.1016/j.jfbs.2011.07.001

Nadkarni, S., \& Herrmann, P.O.L. (2010). CEO personality, strategic flexibility, and firm performance: The case of the Indian business process outsourcing industry. Academy of Management Journal, 53(5), 1050-1073. https://doi.org/10.5465/ AMJ.2010.54533196

Park, C.M. (2005). The impact of the firm performance on the SMEs CEO characteristics in Yeongnam area. Journal of Industrial Economics and Business, 18(3), 10751101.

Park, J.W., \& Kim, W.J. (2014). A study on the relationships between HEXACO personality, entrepreneurship and the firm performance. Asia Pacific Journal of Small Business, 36(2), 147-168.

Park, R.Y., \& Seol, H.D. (2011). The effects of favorable job conditions on affective commitment: Focusing on the mediating effects of social exchange relationship. Korean Corporation Management Review, 18(2), 161-185.

Park, S.Y., \& Lee, C. (2011). Development of a competency model for CEO in SMEs. Journal of Agricultural Education and Human Resource Development, 43(1), 87-106. https://doi.org/10.23840/agehrd.2011.43.1.87

Park, W.W., Kim, M.S., Jeong, S.M., \& Huh, K.M. (2007). Cause and remedies of common method bias. Korean Journal of Management, 15(1), 89-133.

Podsakoff, P.M., \& Organ, D.W. (1986). Self-reports in organizational research: Problems and prospects. Journal of Management, 12(4), 531-544. https://doi. org/10.1177/014920638601200408

Rauch, A., \& Frese, M. (2007). Let's put the person back into entrepreneurship research: A meta-analysis on the relationship between business owners' personality traits, business creation, and success. European Journal of Work and Organizational Psychology, 16(4), 353-385. https://doi.org/10.1080/13594320701595438 
Reichard, R.J., Riggio, R.E., Guerin, D.W., Oliver, P.H., Gottfried, A.W., \& Gottfried, A.E. (2011). A longitudinal analysis of relationships between adolescent personality and intelligence with adult leader emergence and transformational leadership. Leadership Quarterly, 22(3), 471-481. https://doi.org/10.1016/j. leaqua.2011.04.005

Rhee, J.H., \& Lim, H.C. (2010). A study on the impacts of HEXACO personality dimensions on job satisfaction and organizational citizenship behavior: Focused on the moderating effects of job autonomy. Korean Journal of Business Administration, 23(2), 791-812.

Seo, Y.S., \& Son, J.M. (2015). A study of effect of CEO innovativeness, organizational learning culture, and the extent of use of information system on firm's innovation performance: Focus on small and medium-sized manufacturing firms in Gimhae. International Business Journal, 26(1), 173-196. https://doi.org/10.14365/ ibj.2015.26.1.7

Shepherd, S., \& Belicki, K. (2008). Trait forgiveness and traitedness within the HEXACO model of personality. Personality and Individual Differences, 45(5), 389-394. https://doi.org/10.1016/j.paid.2008.05.011

Shin, J.H., \& Yang, Y.J. (2010). Study on the global product management and business performance. Korean Corporation Management Review, 17(4), 75-93.

Sinkula, J.M., Baker, W.E., \& Noordewier, T. (1997). A framework for marketbased organizational learning: Linking values, knowledge, and behavior. Journal of the Academy of Marketing Science, 25(4), 305-318. https://doi. org $/ 10.1177 / 0092070397254003$

Song, S.G. (2008). Factors affecting the acceptance of BSC. Korean Accounting Journal, 17(2), 39-64.

Soriano, D.R., \& Castrogiovanni, G.J. (2012). The impact of education, experience and inner circle advisors on SME performance: Insights from a study of public development centers. Small Business Economics, 38(3), 333-349. https://doi. org/10.1007/s11187-010-9278-3

Spain, S.M., Harms, P., \& LeBreton, J.M. (2014). The dark side of personality at work. Journal of Organizational Behavior, 35(S1), 41-60. https://doi.org/10.1002/ job. 1894

Szarota, P., Ashton, M.C., \& Lee, K. (2007). Taxonomy and structure of the Polish personality lexicon. European Journal of Personality, 21(6), 823-852. https:// doi.org/10.1002/per.635

Thong, J.Y., \& Yap, C.S. (1995). CEO characteristics, organizational characteristics and information technology adoption in small businesses. Omega, 23(4), 429-442. https://doi.org/10.1016/0305-0483(95)00017-I

Wasti, S.A., Lee, K., Ashton, M.C., \& Somer, O. (2008). Six Turkish personality factors and the HEXACO model of personality structure. Journal of Cross-Cultural Psychology, 39(6), 665-684. https://doi.org/10.1177/0022022108323783

Won H.S., Hong, J.H., \& Cha, J.H. (2015). An effect on business performance of S\&M business CEOs' entrepreneurship. Journal of Business Education, 29(1), 309-340. 
Yoo, T.Y. (2007). The relationship between HEXACO personality factors and a variety of performance in work organization. Korean Journal of Industrial and Organizational Psychology, 20(3), 283-314. https://doi.org/10.24230/ ksiop.20.3.200708.283

Yoo, T.Y., Lee, K.B., \& Michael C.A. (2004). Psychometric properties of the Korean version of the HEXACO personality inventory. Korean Journal of Social and Personality Psychology, 18(3), 61-75.

You, J.W. (2012). The relationship among academic procrastination, self-regulated learning, fear, academic self-efficacy, and perceived academic control in e-learning. The Journal of Educational Information and Media, 18(3), 249-271.

Yun, S.H., \& Na, S.I (2015). The causal relationship among self-directed learning, metacognition, learning motivation, job characteristics, and organizational open communication of office workers in large corporations. Journal of Agricultural Education and Human Resource Development, 47(3), 203-230. https://doi. org/10.23840/agehrd.2015.47.3.203

Zhao, H., Seibert, S.E., \& Lumpkin, G.T. (2010). The relationship of personality to entrepreneurial intentions and performance: A meta-analytic review. Journal of Management, 36(2), 381-404. https://doi.org/10.1177/0149206309335187 